\title{
Los cristianos nuevos y la Compañía de Jesús: Antonio de Acosta y José de Acosta
}

\author{
Luis Alberto M. Dávila Murguía \\ UNISINOS - Brasil
}

El siguiente estudio se ha dividido en dos partes. En la primera parte se analizan las relaciones de la familia de José de Acosta, especialmente la de su padre, Antonio de Acosta y sus actividades profesionales, así como la incorporación a la Compañía de Jesús de cinco de sus hijos. En la segunda parte se analizan las acusaciones que fueron proferidas contra el jesuita José de Acosta, al que calificaban como cristiano nuevo. Estas acusaciones deben ser analizadas en el contexto de las pugnas por llevar adelante la realización de la Quinta Congregación General de la Compañía de Jesús en Roma en 1593. Estos dos momentos se entrelazan en la vida de José de Acosta cuando se dio el cambio de la política de la Compañía de Jesús en relación con la incorporación de cristianos nuevos en sus filas.

\section{Antonio de Acosta: amico nostro}

Gracias a León Lopetegui y Claudio M. Burgaleta sabemos con certeza que José de Acosta nació en 1540 en la ciudad de Medina del Campo. Su padre era un mercader importante llamado Antonio de Acosta, de posible origen portugués y dedicado al comercio de lana y tejidos en Medina del Campo. Su madre se llamaba Ana de Porres, de familia de comerciantes acomodados dedicados al comercio textil (Parrilla, 2005). Tuvieron nueve hijos y siempre vivieron en Medina del Campo. Lopetegui había declarado que la familia Acosta descendía de judíos portugueses, en especial por el lado paterno, y que las informaciones tenían como origen el periodo alrededor del año de 1593, periodo turbulento debido a las disputas por la convocación a la Quinta Congregación General. De la misma manera, Burgaleta declara que la cuestión sobre los orígenes familiares de Acosta continuaba abierta, ya que no se había encontrado nuevas informaciones (Burgaleta, 1999).

Antonio de Acosta era un mercader que trabajaba dentro de la entidad comercial que unía las ciudades y pueblos: la Mesta, un concejo que regulaba la

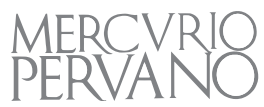


ganadería lanar de la Corona de Castilla. Las caravanas de mercaderes andantes y los pastores nómadas de ovejas de la región se juntaban cada tiempo en cruces de caminos donde, con el pasar del tiempo, se originarían las ferias, como sería el caso de Medina del Campo. Hasta el siglo XIII la circulación de productos se restringía a las ovejas y su lana, el vino y los cereales. Esta circulación de productos atrajo a comerciantes de diversas regiones y nacionalidades $\mathrm{y}$, entre estos, a los judíos. La importancia de esta comunidad se puede medir cuando en el año de 1290 se reunió a todas las aljamas o comunidades judías del reino de Castilla para acordar el tributo que deberían pagar. Solo la ciudad de Medina del Campo, sin considerar pequeños pueblos próximos, contribuyó con 44.000 maravedís, mientras que la ciudad de Valladolid y sus proximidades lo hicieron con casi 70.000 (Ruiz, 1986).

Si bien el panorama político estaba jalonado por una serie de enfrentamientos y disputas entre los reinos y las noblezas de Castilla y de León, la ciudad de Medina del Campo consiguió crecer y aumentar su importancia. La clave de ese crecimiento en el siglo XIV y XV radicaba en la importancia de sus ferias. Un primer impacto que se dio en la ciudad fue el aumento considerable de ciertas actividades relacionadas con la artesanía y con el comercio local, apareciendo en la documentación de la época profesiones como la de joyeros, zapateros, traperos y otros. Al mismo tiempo, se fue gestando un núcleo importante de mercaderes que provenían de diversas regiones. Frente a una sociedad local que seguía regida por importantes linajes locales y conformada por sectores tradicionales como pastores y villanos, fueron ganando importancia hombres de negocios relacionados con el comercio a larga distancia y a actividades de cambio y préstamo, con una importante presencia de extranjeros.

En el caso particular de Medina del Campo, existía una importante comunidad judía. En 1464, ellos contribuyeron con alrededor de 5.000 maravedís al pago del servicio y medio servicio, valor cercano a lo contribuido por las juderías de Valladolid o de Zamora. Esa contribución subiría después hasta 8.000 en 1484 y se mantendría estable durante toda esa década. ${ }^{1}$ El peso de este grupo dentro de la sociedad medinense era importante y según Julio Valdeón Baruque podría explicar por qué en medio de una crisis económica no se dio en Medina del Campo un pogromo contra este grupo en 1391, año en que la Península se vio plagada de ataques contra los judíos (Valdeón, 1986).

Las ferias de Medina del Campo aportan una información adicional relevante. Desde los primeros años en que se iniciaron las ferias en la ciudad (alrededor de la década de 1410) se evidencia la creciente presencia de mercaderes

1 El servicio y medio servicio era un impuesto que surgió para financiar la guerra de reconquista, y por tanto de carácter extraordinario, cobrado a los judíos y mudéjares de Castilla, pero que con el paso del tiempo se convirtió en anual y en un valor fijo, el cual era dividido entre los miembros de las minorías religiosas (Ferreiro, 2002). 
portugueses. Con motivo de la celebración de las Cortes de Palenzuela en 1425, se menciona el papel de comerciantes portugueses dentro de las ferias. En estas Cortes se confirmó la casi excepción del pago de impuestos en las ferias castellanas por parte de los mercaderes portugueses, resolución que sería después confirmada por los Reyes Católicos en 1484. La gran presencia de portugueses en las ferias de Medina del Campo los llevó a que contrajesen matrimonio con mujeres castellanas, estrategia que permitía la inserción de estos mercaderes dentro de la propia comunidad, dando lugar a la conformación de linajes y de redes de mercaderes unidos por alianzas matrimoniales (Abed Al-Hussein, 1986b).

Las ferias de Medina del Campo se celebraban dos veces al año (en mayo y octubre), con una duración de 50 días. Circulaban por sus calles numerosos comerciantes portugueses, franceses, flamencos, florentinos y genoveses, así como vascos y navarros. Valdeón Baruque menciona que se comerciaba miel, vino, aceite, perlas, sedas, brocados, lienzos, especias y esclavos pero principalmente se comerciaba lana. Al mismo tiempo, destaca que se desarrollaba un importante uso de letras de cambio (Valdeón, 1986).

El supuesto origen portugués de Antonio de Acosta tendría apoyo en el propio desarrollo de la actividad ferial en Medina del Campo. Además es importante observar la constitución de redes de parentesco y alianzas matrimoniales, como sería el caso de su matrimonio con Ana de Porres. Como observa Carmen Parrilla, la mayoría de los miembros de la familia Porres establecieron alianzas matrimoniales con familias de mercaderes y de su mismo rango social (Parrilla, 2005).

Además, las redes que se entretejían a partir de las ferias de Medina del Campo se habían expandido hacia regiones cada vez más distantes. Ahora se mantenían frecuentes e intensas relaciones comerciales con varias ciudades del norte de Europa, constituyendo un doble flujo mercantil: la importación de telas, tejidos y brocados de Flandes y de otras regiones adquiridos fuera de España (y que ahora circulaban dentro de Castilla a partir de las ferias) y la exportación para esas mismas regiones de la lana merina con la que se confeccionaban estos productos y de metales preciosos provenientes de las Indias. En ese sentido, Medina del Campo constituía un nudo de redes internacionales en que circulaban diversas mercancías, dinero, letras de cambio, personas y (por qué no) también ideas.

El 14 abril de 1556 el padre Juan Alfonso de Polanco escribió desde Roma al padre Miguel de Torres sobre un hecho inusitado. Contaba la historia de un mercader residente en Medina del Campo, llamado Antonio de Acosta, el cual tenía nueve hijos, seis varones y tres mujeres, de los cuales entraron a la Compañía cinco varones: Jerónimo, Cristóbal, Diego, Bernardino y José (Monumenta Ignatiana, 1911). El único hijo que no entró en la Compañía fue Hernando de Acosta, el cual serviría en el ejército de Felipe II en campañas en Granada contra

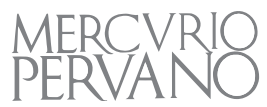


los moros, en Italia y en Flandes y moriría en 1595. Además de esta información, se sabe que dos de sus hermanas entraron en órdenes religiosas, llegando una de ellas (María de Acosta) al cargo de abadesa (Lopetegui, 1942). De la otra hermana (llamada Juana) se conserva la información dada por José de Acosta al responder al cuestionario de Nadal a fines de 1561: «la otra tiene medianamente para casarse y al presente es doncella» (Lopetegui, 1942, p. 613) y otra noticia dada por su hermano Bernardino de Acosta quien informó que para casarse tenía una dote de diez mil ducados (Epistolae p. Hieronymi Nadal, 1898). Los hijos de Antonio de Acosta tuvieron un destino amarrado a la vida religiosa, diferente al suyo. Aparentemente. Ninguno de ellos, hasta lo que se sabe, ejerció la actividad de mercader o comerciante.

En Medina del Campo, los mercaderes eran un grupo social nuevo, los cuales dependían fuertemente de las relaciones familiares. Comportamientos como el de nombrar a alguno de los hijos, principalmente al mayor, como socio de la compañía o como agente de la misma en otras ciudades, eran prácticas comunes. Se buscaba encontrar continuadores del negocio dentro de la propia familia (Abed Al-Hussein, 1986b). Y esos continuadores no existían en los negocios de Antonio de Acosta. Mejor dicho, de forma consciente o no, Antonio de Acosta fue cerrando las puertas del siglo o de las actividades comerciales a sus hijos y las puertas que fue abriendo fueron aquellas que ofrecía la vida religiosa. Para explicar esa elección consciente, es necesario remitirse a otras informaciones.

La noticia recibida por Polanco sobre los hijos de Antonio corrió rápidamente a través de las cartas que circulaban dentro de la Compañía. El jesuita medinense Gaspar de Loarte recibió también sobre este hecho una carta el 16 de abril de 1556 de Ignacio de Loyola, en la cual Antonio de Acosta es llamado amico nostro. Además, se agrega una información importante: Antonio de Acosta se había ofrecido para emprestar una importante suma de dinero para pagar unas deudas contraídas para abrir el Colegio de Roma (Monumenta Ignatiana, 1911). A través de las noticias que circulaban se evidenciaba la intencionalidad de destacar el ejemplo de los hijos del comerciante, el cual no era único. En carta al padre Pedro Ribadeneyra del 12 de mayo de 1556, Loyola mencionaba el caso de los dos hermanos de Fulvio Androzzi, así como de los cuatro hermanos de la ciudad de Pésaro que se hicieron jesuitas y los cinco de Medina del Campo: los Acosta (Monumenta Ignatiana, 1911).

Las menciones a la proeza de haber entrado a la Compañía cinco hermanos son contantemente repetidas y mencionadas con la finalidad de que, a través de las lecturas de estas cartas, se estimulase un movimiento de incorporación de nuevos miembros, edificar el espíritu de los simpatizantes y futuros candidatos para que entraran en la Compañía.

Pero ahora merece la pena detenrse en las palabras dirigidas al padre Gaspar de Loarte, sobre el significado exacto de la expresión amico nostro. Así 
como Antonio de Acosta, Loarte también era de Medina del Campo. Tenemos también la información que Loarte era un cristiano nuevo. ${ }^{2}$ No se puede de olvidar que para Ignacio de Loyola el origen judío o ser un cristiano nuevo no constituía un impedimento para ingresar en la Compañía. Las dificultades encontradas por Gaspar de Loarte para su ingreso en la Compañía, a pesar de la posición favorable de Loyola y de su secretario Jerónimo Nadal, mostraba la oposición interna que existía dentro de la Compañía a la incorporación de cristianos nuevos, algo acorde a la postura del Tribunal de la Inquisición (Maryks, 2010).

Es necesario explorar también la información sobre la suma de dinero prestada para pagar unas deudas de la Compañía por parte de Antonio de Acosta. En carta que escribió el padre Antonio de Aráoz para Juan Alfonso de Polanco desde Valladolid el 24 de febrero de 1556, se relata que el padre Jerónimo Nadal había visitado la ciudad de Medina del Campo con la finalidad de saber cómo estaba el proyecto de levantar el colegio y fue informado de que Antonio de Acosta había ofrecido a la Compañía tres mil ducados de ayuda para el Colegio Romano (Epistolae Mixta, 1908). Además de eso, Antonio había ofrecido un terreno que lindaba con su casa y con el futuro colegio de Medina del Campo con la finalidad de ampliarlo (Litterae Quadrimestres, 1895). Estos ofrecimientos se cumplirían parcialmente.

La modernización que atravesaba Medina del Campo debido al incremento de las actividades mercantiles había hecho de la ciudad un lugar por donde transitaban mercaderes extranjeros. Los propios comerciantes de Medina del Campo al constituir sus compañías comenzaron a adquirir algunas prácticas comerciales provenientes de otros espacios, principalmente del norte de Italia y de Flandes. Los contratos de constitución de las compañías ya no eran solo acuerdos orales sino que se hicieron detallados acuerdos comerciales en que se incorporaban diversas obligaciones y deberes de los socios, se colocaban los objetivos de la sociedad, con fecha de inicio y de fin, así como se informaba sobre la distribución de cuotas entre los socios. El uso extensivo de las letras de cambio ya significaba la expresión de intensas relaciones comerciales con otros espacios fuera de Castilla (Abed Al-Hussein, 1986b). El propio ofrecimiento de Antonio de Acosta de los tres mil ducados es una expresión de cómo el comercio en Medina del Campo había provocado determinadas mudanzas. Antonio se ofrecía a prestar a la Compañía 3.000 duca-

2 Es interesante leer la carta de Gaspar de Loarte y Diego de Guzmán al padre Antonio de Aráoz en la cual le presentan el problema de la posibilidad de que se niegue su ingreso a la Compañía por motivo de ser Loarte de linaje nuevo: «por algunas causas parecía á V. P. no conuenir por aora nuestra entrada en la Compañía, aunque sabemos que lo que se pone por inconueniente no lo es acerca de V. P., ni le agrada tal manera de sentir en varones tan euangélicos». Carta de Gaspar de Loarte y Diego de Guzmán para Antonio de Aráoz, 13 de julio de 1553 (en Epistolae Mixta, 1900, pp. 392-394).

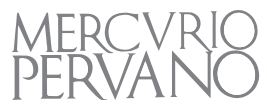


dos, moneda que solamente podía ser usada para transacciones externas. Ese valor sería otorgado a través de una letra de cambio que sería otorgada por medio de un corresponsal que se encontraba en Valencia y que luego sería cobrada en Roma (Monumenta Ignatiana, 1911). Además, el padre Francisco de Borja a Ignacio de Loyola (en una carta escrita el 26 de febrero de 1556, al mencionar el dinero ofrecido por Acosta que sería enviado de Valencia a Roma) destacaba que el ducado pagado en el destino final sería cotizado casi a un tercio a más, lo cual era altamente ventajoso (Monumenta Borgia, 1908). En ese sentido, Antonio de Acosta era un mercader que se encontraba dentro de los nuevos ejes de comercio que conectaban las ferias de Medina del Campo con otras plazas castellanas y europeas.

En 1540, el mismo año del nacimiento de su hijo José, se tiene noticias de que Antonio constituyó por escrito una compañía. Tenía como finalidad el comercio de paños y telas en la propia región de Medina del Campo. La compañía estaba integrada por tres socios: el propio Antonio que participaba con $450 \mathrm{mil}$ maravedís, equivalentes a 3 partes y media de la sociedad; Juan Criado que había aportado 250 mil maravedís y representaba 2 partes y media, y por último, Lucas Fresno, el cual no había aportado capital. Antonio había cedido una parte de la sociedad para contar con su apoyo en las actividades. Por el volumen del capital empleado, era una compañía pequeña que operaba en el comercio a escala local y quizá en algún momento a escala regional. La compañía de Antonio tendría una duración de siete años establecida en el contrato de abertura, lo cual era una práctica común. No tenemos información sobre si la compañía fue o no renovada (Abed Al-Hussein, 1986b).

En una carta de Francisco de Borja, describe que Antonio «anda muy caído» al referirse sobre el dinero prometido y que no había podido cumplir con sus compromisos financieros con la Compañía (Monumenta Borgia, 1908). La carta fue escrita en 1557. A partir de 1550 se inició un periodo de crisis económica por toda la Península y que afectó en especial a los mercaderes y sus compañías. No se puede olvidar que la Corona atravesaba por problemas urgentes derivados de los conflictos que se arrastraban en Alemania, Francia e Italia. La gran cantidad y excesivos valores de préstamos pedidos por la Corona hasta el año de 1556 y el no cumplimiento de los pagos llevaron a una crisis gigantesca. Los préstamos solicitados tenían como principal destino el mantenimiento de los ejércitos en el exterior. Esta falta de dinero en el interior del territorio (sea en la forma de numerario, préstamos o de capitales) tuvo como consecuencia inmediata el aumento de los intereses cobrados. Esto llevaría a una grave crisis entre los mercaderes que actuaban en las ferias de Medina del Campo. El número de bancarrotas entre los mercaderes y de banqueros de la ciudad sería considerable tanto en número como en valores en relación con el resto de Castilla (Abed Al-Hussein, 1986c). 
La crisis por la cual atravesaban las ferias de Medina del Campo en el año de 1557 podía explicar en buena parte las dificultades de Antonio de Acosta en relación con su ofrecimiento de un préstamo para la Compañía. La actitud de Antonio de haber intentado realizar un préstamo para la Compañía no era un acto aislado. Consideremos el caso de su paisano Pedro Cuadrado, mercader que actuaba en Flandes y que había conocido a Ignacio de Loyola en Amberes en la casa del comerciante segoviano Juan de Cuéllar, el cual era visto como un seguidor de los alumbrados. Años después, ya de regreso a Medina del Campo, en el año de 1557, fundaría junto con su mujer, Francisca Manjón, el colegio de la Compañía en Medina del Campo (Borja, 1999). Antonio de Acosta, al no poder realizar el préstamo para la Compañía, ofreció una huerta al lado de su casa con la finalidad de ampliar el Colegio de Medina del Campo.

En carta escrita por Jerónimo Nadal para el padre Jacobo Laynez desde Toledo en 1561, se hace una referencia importante: «El juro del P. Francisco se acaba en Mayo, y déuense dos años menos dos meses del tiempo de la rotura de Antonio de Acosta» (Epistolae p. Hieronymi Nadal, 1898, p. 411). Es decir que alrededor de 1558 o 1559, la compañía de Antonio de Acosta quebró. Posteriormente, en 1567, tenemos la carta del mismo Nadal para el padre Francisco de Borja en la que consulta:

Otros tienen algunos impedimentos, que nos hazen dubdar. Entre los quales es vno el doctor Diego de Acosta, que quanto a su persona y doctrina, estoy bien satisfecho, y a su pulpito también; mas he entendido que en Anuers tiene vn tio, llamado Francisco de Porras, que es corredor, y no bien quisto, sino al contrario. Tememos que éste le haría no ser tenido en lo que conuiene a vno que predica, etc.; y también por auer su padre quebrado en España, que entre mercaderes, en Anuers, sabe no a buen nombre (Epistolae p. Hieronymi Nadal, 1902, p. 541).

A estas alturas se podría pensar que una de las estrategias de Antonio de Acosta fue aproximarse a la Compañía con la finalidad de obtener seguridad y estabilidad. Si el origen de su familia era converso, la Compañía representaba al principio un espacio de convivencia lejos de posibles persecuciones o acosos. Basta pensar en los medinenses que habiendo sido aceptados en la Compañía, eran de origen judío: Gaspar de Loarte, Baltasar de Torres, Gregorio de Valencia, José de San Julián, así como los comerciantes Pedro Cuadrado y Rodrigo de Dueñas, donantes del Colegio de los jesuitas en Medina del Campo, además de los Acosta. ${ }^{3}$ Para Robert A. Maryks, existe una clara tendencia dentro de las

3 El papel de Rodrigo de Dueñas fue importante para el establecimiento de la Compañía en Medina del Campo. Miembro del Consejo de Hacienda del emperador Carlos V y habiendo conocido a los padres Pedro Fabro y Antonio de Aráoz en años anteriores, ofreció por medio de una carta dirigida al padre Miguel de Torres, el mantenimiento de seis miembros de la Compañía en la ciudad. Su pedido fue aprobado en 1551. Cumplido el objetivo de que la Compañía enviase miembros para fundar el colegio, Dueñas retiraría el ofrecimiento principal

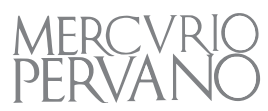


familias conversas de asimilarse al nuevo panorama castellano posterior a la expulsión decretada por los Reyes Católicos. Con el surgimiento de la Compañía de Jesús, ésta es vista como un espacio de sociabilización y de estabilidad. Muchos se incorporarían a sus filas como religiosos, pero también como financistas de sus colegios, residencias y de obras pías patrocinadas por la Compañía (Maryks, 2010).

Lo que podría parecer parte de un habilidoso mecanismo de supervivencia social por parte de grupos minoritarios y perseguidos puede también ser el caso de una conversión sincera al catolicismo. En ese sentido, los motivos de seguridad y estabilidad, desde un punto de vista material o económico, serían ajenos a esta consideración (Levi, 1996/1997).

Ya en 1554, cuatro hijos de Antonio de Acosta se encontraban en la Compañía y en 1556, su hijo mayor, Jerónimo, entraba en la misma. ${ }^{4} \mathrm{El}$ ingreso de los hijos se había efectuado antes de que estallase la crisis y la quiebra de parte de los negocios de Antonio de Acosta. José de Acosta recuerda que, con trece años y ya militando dentro de la Compañía, el espíritu que la Compañía había impregnado a su familia. En una carta dirigida a Ignacio de Loyola, escrita en Medina del Campo el 31 de mayo de 1554 (Litterae Quadrimestres, 1896), se refiere a una reunión que se realizó en Medina del Campo por motivo de la división de España en provincias jesuíticas y que reuniría a los padres Jerónimo Nadal, Francisco de Borja, Miguel de Torres, Antonio de Aráoz y Francisco de Estrada en la casa de su padre Antonio en abril de 1554. La excitación de la reunión se

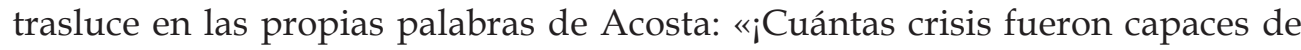
salir de nuestros corazones! ¡Con lo que todos se maravillaron! ¡Oh buen Jesús!» El espíritu que se compartía era de fraternidad, caridad y edificación. Y ese sentimiento es el que invadiría a toda la familia Acosta. No por casualidad, dos años después, Jerónimo (que por ser el mayor de los hijos de Antonio y tener la responsabilidad tradicional de continuar con los negocios comerciales de su padre) dejó los negocios para entrar en la Compañía. ${ }^{5}$

\footnotetext{
y solo daría un valor como limosna. Posteriormente en 1553, el mismo Dueñas entregaría una casa en donación para que fuese establecido el colegio. Es importante mencionar que los cuatro hijos de Rodrigo de Dueñas, así como los de Antonio de Acosta, entrarían en este nuevo colegio (ver Astrain, 1912.).

4 De la visita realizada por el padre Nadal por la Península entre mayo de 1553 y terminada antes de octubre de 1554, realiza un catálogo de los jesuitas de España en el cual consigna a los cuatro hermanos Acosta, destacando que en 1554 Bernardino de Acosta ya era hermano dentro de la Compañía, por tanto, fue el primero en entrar en la Compañía (ver Astrain, 1912).

5 «De manera general, los historiadores dan por hecho que todo sistema normativo sufre transformaciones con el tiempo, pero que en un momento dado se vuelve plenamente coherente, transparente y estable. Me parece, al contrario, que deberíamos interrogarnos más sobre la amplitud real de la libertad de elección. Desde luego, esta libertad no es absoluta: cultural y socialmente determinada, limitada, conquistada pacientemente, sigue siendo sin embargo una libertad consciente que los intersticios inherentes a los sistemas generales de normas dejan a
} 


\section{José de Acosta: «en darle en todo con su genealogía y ambición»}

A partir del análisis de la documentación de los archivos jesuitas en Roma, el jesuita León Lopetegui, afirmaba que no existía ninguna mención sobre el origen judío de José de Acosta hasta antes del año de 1593. Razón de la importancia de este año radica en el contexto que rodeó las negociaciones y presiones realizadas por Felipe II y por su delegado especial, José de Acosta, para que se realizara la convocación a la Quinta Congregación General de la Compañía de Jesús. ${ }^{6}$ Del mismo parecer también es Claudio M. Burgaleta. ${ }^{7}$

José de Acosta llegó a España en setiembre de 1587. Había permanecido durante un año en México, después de haber estado catorce años en el Perú. Cargaba con la experiencia de haber sido provincial de la Compañía en el Perú y de haber participado de manera notable en la realización del III Concilio Limense entre 1582 y 1583. Llevaba para España el proyecto de publicar dos manuscritos escritos en el Perú, De procuranda indorum salute y su Natura Novi Orbis, los cuales serían publicados en un solo libro en 1588. Posteriormente tomando como base el manuscrito Natura Novi Orbis y adicionando las informaciones proporcionadas por el licenciado Polo de Ondegardo y por el jesuita Juan de Tovar, publicaría la Historia natural y moral de las Indias en 1590. Pero, principalmente, buscaba obtener la aprobación del texto integral y de los decretos aprobados en el III Concilio Limense. Su fama ya le antecedía con mucho su llegada. El general Claudio Acquaviva escribía al padre Gil González el 21 de noviembre de 1587: «Gracias a Dios que son llegados los indianos con salud y las flotas con prosperidad... del P. José de Acosta creo bien que tiene todas las buenas partes que V. R. dice, y en este concepto le tengo yo después que he visto algunas cosas suyas; yo le deseo y espero porque nos consolaremos todos con su presencia» (Lopetegui, 1942, pp. 583-584).

Desde su llegada a España hasta septiembre de 1588, Acosta se detendría en Madrid entre la corte de Felipe II y las reuniones dentro del Consejo de Indias con la finalidad de informarles sobre los graves problemas que enfrentaban sus reinos americanos y en especial, los problemas relacionados a las encomiendas, los tributos, las minas y los indios. Partiría después para Roma para entrevistar-

\footnotetext{
los actores. Ningún sistema normativo es, de hecho, lo bastante estructurado como para eliminar toda posibilidad de elección consciente, de manipulación o de interpretación de las reglas, de negociación» (Levi, 1996/1997, p. 23).

6 Lopetegui menciona la posible existencia de informes secretos que se encontraban separados del resto de los informes y que tenían informaciones sobre la historia de cada candidato a la Compañía y su recorrido dentro de ella. Al mismo tiempo, afirma el autor, no haber encontrado ningún rastro de este tipo de documentación (ver Lopetegui, 1942).

7 Burgaleta afirma que el padre León Lopetegui, en relación con el origen portugués y judío de Acosta, no proporcionó ningún documento que pudiese aclarar su origen, sino solamente se fundamentó en los ataques realizados con motivo de la Quinta Congregación (ver Burgaleta, 1999).
}

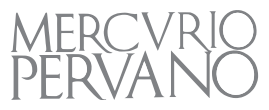


se con el general Acquaviva, el cual le encargaría importantes negociaciones que debería realizar frente a Felipe II, motivo por el cual regresaría luego a Madrid. De estos vaivenes y negociaciones, ocurridos antes de 1592, lo que estaba en cuestión era la autonomía de la Compañía de Jesús en relación con la Corona y al Tribunal del Santo Oficio español. A pesar de ser hombre de confianza de la Compañía, Acosta sería designado como agente de Felipe para realizar negociaciones frente al nuevo Papa, Clemente VIII, con la finalidad de convocar a la Quinta Congregación y de defender los intereses de la Corona frente al Papado y a la Compañía.

El principal escollo para la convocatoria era la oposición tenaz del propio Acquaviva que era contrario a cualquier reforma de los privilegios y exenciones de la Compañía. Sensible a los nuevos aires políticos, en especial al carácter confesionalista $^{8}$ de la política de Felipe II en temas que corresponden a la relación entre Corona e Iglesia, el General se oponía a la designación de comisarios y visitadores nombrados por la Corona con autonomía en relación al general de la Compañía ya que, a su entender, eso llevaría a la división de los intereses de la Compañía en su conjunto, por lo cual propugnaba que estas autoridades estuviesen sujetas al control del general, y por ende, del propio Papa. Al mismo tiempo, Acosta favorecía en sus negociaciones la necesidad que la Compañía no se opusiese a la Inquisición y que reconociese para sí los mismos privilegios y exenciones que tenían las otras órdenes religiosas (De la Pinta, 1952). En ese conflicto se reflejaba el significado de lo español en la Compañía en relación con la presencia cada vez más importante de miembros no españoles que buscaban restringir su influencia.

Frente a la acción diplomática de la Corona en Roma, se levantó una operación organizada por el propio general Acquaviva para socavar la labor de Acosta en favor de la convocatoria de la Congregación. Una de sus primeras acciones sería la expulsión de Acosta de la casa profesa, residencia principal, y en la cual vivía el propio Acquaviva, para trasladarlo a la Penitenciaria. Acosta afirmaría que «su principal intento, ha sido quitarme la reputación con los de la Compañía, y con los de fuera, para que en los negocios que tengo a cargo se haga poco caso de mí y según me han avisado ha comenzado por aquí con intento de pasar muy adelante, para lo cual he entendido que ha informado largamente al Papa, y escrito a los suyos para que también informen a V. Majestad» (De la Pinta, 1952, p. 54).

A pesar de las resistencias Acquaviva fue derrotado en lo que se refiere a la convocatoriade la Congregación. El Papa Clemente VIII, el 15 de diciembre de 1592, convocó a la realización de la Congregación con la finalidad de realizar un

\footnotetext{
8 Sobre la discusión de la noción de confesionalización, es interesante discutir el término a partir de la lectura de Heinrich Lutz (1992), así como de las reflexiones sobre su uso para entender el gobierno de Felipe II en España, a través de Martínez Millán (1994-1995).
}

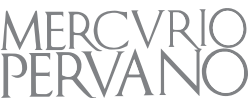


estudio profundo de los males que acechaban a la Compañía y que habían sido denunciados anteriormente por algunos de sus miembros de forma anónima, en especial aquellos que eran conocidos como memorialistas. ${ }^{9}$

A pesar del resultado de la convocatoria, Acquaviva continuaba su campaña contra Acosta. En carta recibida por Felipe II por parte del Tribunal de la Inquisición el 13 de marzo de 1593 se dice: «En cuanto a la confianza que pretende se haga de su persona en las materias de Inquisición, parece negocio muy dificultoso y lleno de sospechas e inconvenientes, por ser los dichos de la cualidad que son, y así el Inquisidor General y el Consejo son del mismo parecer» (De la Pinta, 1952, pp. 66-67).

El aviso de la Inquisición se refería tanto a Acosta como al futuro cardenal Francisco de Toledo, también miembro de la Compañía y descendiente de una familia conversa judía. Por tanto, a partir de un miembro de la Compañía del que se sabía notoriamente que era cristiano nuevo, se hacía la relación con Acosta, sobre el cual no había informaciones.

El 2 de noviembre de 1593 comenzaba la Quinta Congregación General. A pesar de la resistencia del General, la mayoría de las propuestas apoyadas por la Corona y por la Inquisición española fueron aprobadas, como la abolición de los privilegios y exenciones de la Compañía en relación con el Santo Oficio, las materias relacionadas a las herejías y sobre las solicitaciones sacramentales.

Pero un triunfo obtuvo el general Acquaviva fue la prohibición de admitir en la Compañía a cristianos nuevos, fuesen de origen judío o de origen sarraceno. ${ }^{10}$ Esta decisión era contraria a aquello que pensaba el propio Ignacio de Loyola. El padre Juan Alfonso de Polanco, en carta escrita desde Roma al padre Antonio de Aráoz el 14 de agosto de 1553, afirmaba que «si allá por los humores de la Corte ó del rey no pareciere que se deban admitir, imbíense acá, siendo buenos supósitos, como ya está escrito otras vezes, que acá no se mira tan al sotil de qué raça sea el que se vey ser buen supósito, como tampoco basta, para que vno se accepte, la nobleza, si las otras partes no concurren» (Monumenta Ignatiana, 1907, p. 335).

\footnotetext{
9 Los memorialistas recibieron este nombre debido a las críticas que circularon mediante memoriales escritos de manera anónima a los cuales se agregaba una relación de miembros de la Compañía que eran partidarios de los puntos contenidos en los mismos. Sus críticas en relación con la Compañía podían ser agrupadas en la necesidad de establecer un gobierno jesuita en España, más independiente del generalato y dando prerrogativas a los provinciales, buscando reducir la autoridad de Roma. Junto a ello se daban críticas a ciertas verdades de la Compañía como la obediencia, la jerarquía interna y principalmente, la necesidad de establecer el estatuto de limpieza de sangre.

10 En la Quinta Congregación se aprobarían los estatutos de limpieza de sangre. Contra el espíritu de las Constituciones de la Compañía se prohibió el ingreso de cristianos nuevos, tanto los de origen judío como musulmán. Posteriormente, en la Sexta Congregación en 1608, se exigiría a los candidatos a la Compañía que presentasen pruebas de la pureza de su sangre hasta la quinta generación (ver Coello, 2011).
} 
Esta decisión provocada por Acquaviva, si bien no afectaba directamente a Acosta o al recién nombrado cardenal Francisco de Toledo, sonaba como una advertencia a todos aquellos miembros de la Compañía que eran de linaje moderno y que eran acusados de ser parte del grupo llamado memorialistas. ${ }^{11}$

El general Acquaviva había decidido nombrar el 11 de setiembre de 1592 al padre Alonso Sánchez como su enviado especial en misión en Madrid. ¿Cuál era el problema de ese nombramiento? La historia de Sánchez con la de Acosta se entrecruza en México en 1586 y 1587. Sánchez había llegado primero a México en 1579 para luego partir en misión para las Filipinas en 1581 en una de las primeras misiones de los jesuitas a estas islas. Estando en las Filipinas, efectuó importantes labores, realizando viajes por el litoral de la China y tuvo un importante papel en el reconocimiento al gobierno de Felipe II por parte de los portugueses que se habían establecido en Macao. Fruto de su experiencia en Filipinas y en la China, Sánchez había elaborado un proyecto de evangelización por medio de la guerra y conquista. Su propuesta era totalmente antagónica a la propuesta que Acosta había elaborado en su manuscrito De procuranda Indorum Salute de una evangelización pacífica. El provincial de la Compañía en México, Antonio Mendoza, en carta escrita el 17 de enero de 1585, advertía al general Acquaviva sobre el peligro que conllevaba el proyecto de Alonso Sánchez de una posible conquista por las armas de la China como por lo que «Verdad que en la relatión que envía de su viaje, nos ha acá desagradado la doctrina que mezcla y la fuerça que pone en fundar que, con praedicatión pacífica, no se hará nada en la China, y que es necessario y muy lícito llevar exército para conquistarla: que assí lo llama él» (en Zubillaga, 1959, pp. 437-438).

La manera como Acquaviva buscó neutralizar la iniciativa de Sánchez de llevar a cabo una embajada en Madrid para exponer sus planes al rey Felipe II y de presentarle sus proyectos, fue la de nombrar un superior inmediato. La infausta tarea recaería sobre el propio José de Acosta. Los dos se encontraban en México de pasaje hacia Madrid. Los dos tenían sus propios proyectos de evangelización que eran diametralmente opuestos. Al nombrar a Acosta como su superior, y sabiendo de los proyectos divergentes de los dos, Acquaviva desautorizaba al propio Sánchez en cualquier tentativa de comunicar su proyecto. Acosta, al mismo tiempo, sabedor que una iniciativa como esa podría estropear el trabajo que la Compañía realizaba en el Oriente (en especial en algunas ciudades de Japón), y que además era contraria a la forma de evangelización que él propondría en su De procuranda para las naciones que él consideraba como semejantes a los griegos y romanos, tomaría la iniciativa de enviar para el propio Felipe dos tratados escritos en los que criticaba el proyecto de Sánchez a partir de una visión teológica y jurídica (Olle, 2000). Resumiendo: la desavenencia en-

11 El jesuita Antonio Astrain hace notar que la mayoría de los llamados memorialistas eran de linaje nuevo o moderno. En la votación de la aprobación del decreto, fueron 62 a favor contra 2 votos, siendo uno de los votos el de José de Acosta (ver Astrain, 1909). 
tre los dos jesuitas partiría de una cuestión política anterior, el proyecto de la conquista armada de la China. Sánchez se sintió desautorizado y al mismo tiempo humillado. Y el general Acquaviva sabía de ese sentimiento.

La oportunidad de Alonso Sánchez se la daría el propio Acquaviva al nombrarlo su enviado especial. Los ataques de Sánchez a Acosta se dieron en un plano personal, buscando desvirtuar su carácter. La oportunidad la tuvo el 22 de marzo de 1593 en audiencia que sostuvo con el propio rey Felipe II. Al tratar sobre la convocatoria de la Quinta Congregación y el papel desempeñado por Acosta, Sánchez manifestó de forma directa que, debido al hecho de que Acosta era cristiano nuevo, se debía tener en cuenta que «ninguno, tarde o temprano, dejo de descubrir el pelo». Lo caracterizó como un padre «ambicioso» por su linaje nuevo, así como detalló su vida regalada y soberbia, en la cual buscaba ser atendido por muchos. Las visitas administrativas que había realizado en las provincias de España fueron descritas como superficiales y apresuradas. Declaró que Acosta tenía como ambición en la Compañía ser nombrado provincial de alguna de las provincias de España. Lo que Sánchez buscaba era resaltar la doblez del carácter de Acosta al afirmar que «según me dijo un grande de esta corte, Acosta ha engañado altamente á Vuestra Majestad, porque le ha hecho entender que ayuda á lo bueno y buenos y cristianos viejos de la Compañía, y no lo hace, sino á los pocos y malos y nuevos» (Astrain, 1909 ,543). Sánchez buscaba colocar como causa de los conflictos que se daban dentro de la Compañía, y en especial en relación con la Congregación, a un grupo pequeño de cristianos nuevos que actuaban con espíritu de cuerpo contra la propia Compañía.

A pesar de la posición favorable que desde un comienzo había manifestado el propio Ignacio de Loyola en relación con la incorporación de los cristianos nuevos dentro de la Compañía, el momento en el cual se organizaba la Quinta Congregación y las disputas que giraban alrededor de ella, llevaron a la discusión sobre la necesidad de impedir el ingreso de cristianos nuevos. El General y su grupo establecieron una relación directa entre aquellos que se oponían a su gobierno dentro de la Compañía con cuestiones personales o nacionales. Acosta se opuso al decreto que impedía la incorporación de cristianos nuevos tomando como inspiración el espíritu que Ignacio de Loyola había dado a la Compañía en los primeros tiempos de su organización. La interpretación de historiadores, como sería el caso del jesuita español Antonio Astrain, era que su oposición se debía simplemente a que él era cristiano nuevo.

Como resumen de esta campaña contra José de Acosta, se pude mencionar la frase de una carta del padre Gil González dirigida a Acquaviva, el 6 de junio de 1594, en la cual figuran las líneas estratégicas del combate que trabaron contra Acosta: «que condenaron mucho el oficio que hacía el P. Alonso Sánchez en darle en todo con su genealogía y ambición» (Lopetegui, 1942, p. 481). 


\section{Conclusiones}

Con lo declarado por León Lopetegui y por Claudio Burgaleta y hasta el momento presente no existen pruebas documentales que pudieran comprobar la condición de cristiano nuevo de José de Acosta y su familia. Al mismo tiempo, el análisis de las actividades mercantiles de Antonio de Acosta nos permite introducirnos en un contexto delineado por circuitos y redes que se entretejían a partir de Medina del Campo y que se expandían al ritmo de los flujos comerciales. Lo que obtenemos es una información valiosa de cómo Antonio de Acosta y su familia fueron entretejiendo relaciones con la Compañía de Jesús y que llevaría a la incorporación de la mayor parte de sus hijos a la vida religiosa.

El análisis de las acusaciones que recayeron sobre José de Acosta a partir de su esfuerzo por convocar a la Quinta Congregación General en 1593 no presenta informaciones sustanciales y se basan principalmente en comentarios hechos por otros padres de la Compañía con la finalidad de fragilizar su posición dentro de la Congregación. Al mismo tiempo, estas acusaciones tuvieron como una de sus consecuencias principales desviar la atención del cambio concreto que se dio en la Compañía de Jesús en relación con la incorporación de conversos dentro de la Compañía. Así, la posición de José de Acosta en la Congregación pasó a ser vista como una defensa de los memorialistas por ser en su mayoría conformada por cristianos nuevos, y no por lo que realmente era: una defensa de un principio de las Constituciones de la Compañía que aceptaba como miembros a hombres de diversos orígenes y linajes.

\section{Referencias bibliográficas}

Abed Al-Hussein, F. H. (1986a). «El comercio de los géneros textiles: seda, paños y lienzos». En Lorenzo Sanz, E. (coord.). Historia de Medina del Campo y su tierra. Auge de las Ferias. Decadencia de Medina. Valladolid: Ayuntamiento de Medina del Campo tomo ii.

Abed Al-Hussein, F. H. (1986b). «Las compañías o asociaciones de mercaderes». En Lorenzo Sanz, E. (coord.). Historia de Medina del Campo y su tierra. Auge de las Ferias. Decadencia de Medina. Valladolid: Ayuntamiento de Medina del Campo tomo ii.

Abed Al-Hussein, F. H. (1986c). «Las quiebras de los hombres de negocios castellanos». En Lorenzo Sanz, E. (coord.). Historia de Medina del Campo y su tierra. Auge de las Ferias. Decadencia de Medina. Valladolid: Ayuntamiento de Medina del Campo tomo ii.

Astrain, A, (1909). Historia de la Compañía de Jesús en la asistencia de España. Madrid: Sucesores de Rivadeneyra, tomo iii. 
Astrain, A. (1912). Historia de la Compañía de Jesús en la asistencia de España. Madrid: Sucesores de Rivadeneyra, tomo i.

Borja Medina, F. (1999). «Íñigo de Loyola y los mercaderes castellanos del norte de Europa. La financiación de sus estudios en la Universidad de París». Hispania Sacra, 51, n. ${ }^{\circ}$ 103, 159-206.

Burgaleta, C. M. (1999). José de Acosta, S.J. (1540 -1600) His Life and Thought. Chicago: Loyola Press.

Coello de la Rosa, Alexandre (2011). «El Estatuto de Limpieza de Sangre de la Compañía de Jesús (1593) y su influencia en el Perú Colonial». Archivum Historicum Societatis Iesu, v. LXXX, fascículo 159, 45-76.

De la Pinta Llorente, M. (1952). Actividades diplomáticas del P. José de Acosta. En torno a una politica y a un sentimiento religioso. Madrid: CSIC.

Epistolae Mixta (1900). Madrid: Excudebat Augustinus Avrial, tomo iii.

Epistolae Mixta (1901). Madrid: Excudebat Augustinus Avrial, tomo v

Epistolae p. Hieronymi Nadal (1898). Madrid: Typis Augustinis Avrial, tomo i

Epistolae p. Hieronymi Nadal (1902). Madrid: Typis Augustinis Avrial, tomo iii.

Levi, G. (1996/1997). «Los usos de la biografía». Historias, 37, 14-25.

Litterae Quadrimestres (1895). Madrid: Excudebat Augustinus Avrial, tomo ii.

Litterae Quadrimestres (1896). Madrid: Excudebat Augustinus Avrial, tomo iii.

Lopetegui, León (1942). El padre José de Acosta S.J. y las misiones. Madrid: CSIC.

Lutz, Heinrich (1992). Reforma y Contrarreforma. Madrid: Alianza.

Martínez Millán, J. (1994/1995). «El confesionalismo de Felipe II y la Inquisición». Trocadero, 6-7, 103-124.

Maryks, R. (2010). The Jesuit Order as a Synagogue of Jews. Jesuits of Jewish Ancestry and Purity-of-Blood Laws in the Early Society of Jesus. Leiden: Brill.

Monumenta Borgia (1908). Madrid: Typis Gabrielis Lopez del Horno, tomo iii.

Monumenta Ignatiana. Series Prima (1907). Madrid: Typis Gabrielis Lopez del Horno, tomo $\mathrm{v}$.

Monumenta Ignatiana. Series Prima (1911). Madrid: Typis Gabrielis Lopez del Horno, tomo xi.

Olle, M. (2000). La invención de China: Percepciones y estrategias filipinas respecto a China durante el siglo xvi. Wiesbaden: Harrassowitz Verlag, 2000.

Parrilla, C. (2005) «El tratado llamado Notable de amor: en torno a una clave de lectura». En López Castro, A (ed.). Actas del XI Congreso Internacional de la Asociación Hispánica de Literatura Medieval. León: Universidad de León, vol. I.

Ruiz Asencio, José M. (1986). «Medina del Campo en la Alta Edad Media (siglos VIII-XIII)». En Lorenzo Sanz, E. (coord.). Historia de Medina del Campo y 
su tierra. Nacimiento y expansión. Valladolid: Ayuntamiento de Medina del Campo, tomo I.

Valdeón Baruque, J. (1986). «Medina del Campo en los siglos XIV y XV». E Lorenzo Sanz, E. (coord.). Historia de Medina del Campo y su tierra. Nacimiento y expansión. Valladolid: Ayuntamiento de Medina del Campo, tomo I, 1986.

Viñuales, Ferreiro (2002). «Los repartimientos del «servicio y medio servicio» de los judíos de Castilla de 1484, 1485, 1490 y 1491». Sefarad, 62, 185-206.

Zubillaga, F. (ed.) (1959). Monumenta mexicana. Roma: MHSI, tomo II. 